\title{
O POVO MONGOIÓ: DA LEMBRANÇA AO ESQUECIMENTO NAS REPRESENTAÇÕES DOS MORADORES DA CIDADE DE ITAPETINGA-BA
}

\author{
El PUEBLO MONGOIÓ: DEL RECUERDO AL OLVIDO EN LAS \\ REPRESENTACIONES DE LOS HABITANTES DE LA CIUDAD DE \\ ITAPETINGA-BA
}

Jussara Tânia Silva Moreira

Universidade Estadual do Sudoeste da Bahia-UESB

\section{Resumo}

O objetivo desse artigo é considerar que mesmo sendo negado oficialmente, existe na cidade de Itapetinga-BA uma memória que mostra a ancestralidade do povo Mongoió (Kamakan) no local. Para tanto, partimos dos dados de nossas pesquisas, sobretudo, da nossa tese de doutoramento quando analisamos entre os anos de 1938 a 2013, a origem e a consolidação dos Batistas na constituição do desenvolvimento urbano de Itapetinga; buscando compreender, como ocorreu esse processo de estabilização religiosa na cidade. Em decorrência desta investigação, do elemento cultural-religioso e da economia pecuarista da cidade, percebemos uma dicotomia entre os discursos oficiais e as lembranças dos recordadores sobre os indígenas. Tal perspectiva, assinalou para o conceito de campo, de representação e de capital cultural, encontrados na contribuição bourdieusiana, quando reconhece que o mundo social está condicionado por estruturas objetivas, independentes da consciência e da vontade do ser humano. Assim, a luz da abordagem qualitativa e da utilização do instrumento metodológico da memória chegamos as lembranças dos homens e das mulheres itapetinguenses, que sem abandonar a atualidade, acabou por trazer à tona as provas da existência do indígena no passado local.

Palavras-chave: Campo. Religião. Cultura. Indígena. 


\section{Resumen}

El objetivo de ese artículo es considerar que aún siendo negado oficialmente, existe en la ciudad de Itapetinga-BA una memoria que muestra la ancestralidade del pueblo Mongoió (Kamakan) en el local. Para tanto, partimos de los datos de nuestras investigaciones, principalmente, de nuestra tesis de doutoramento cuando analizamos entre los años de 1938 a 2013, el origen y la consolidación de los Batistas en la constitución del desarrollo urbano de Itapetinga; buscando comprender, como ocurrió ese proceso de estabilización religiosa en la ciudad. En el transcurso de esta investigación, del elemento culturalreligioso y de la economía pecuarista de la ciudad, percibimos una dicotomia entre los discursos oficiales y los recuerdos de los recordadores sobre los indígenas. Tal perspectiva, señaló para el concepto de campo, de representación y de capital cultural, encontrados en la contribución bourdieusiana, cuando reconoce que el mundo social esta condicionado por estructuras objetivas, independientes de la conciencia y de la voluntad humana. Así, la luz del abordaje cualitativo y de la utilización del instrumento metodológico de la memoria llegamos los recuerdos de los hombres y de las mujeres itapetinguenses, que sin abandonar la actualidad, acabó por sacar a la luz las pruebas de la existencia del indígena en el pasado local.

Palabras clave: Campo. Religión. Cultura. Indígena.

\section{Introdução}

Ao defender a ancestralidade do povo Mongoió (Kamakan), como os primeiros habitantes de Itatinga (a Pedra Branca) ${ }^{\mathrm{i}}$, reconhecemos que após os confrontos no Sertão da Ressaca $^{\mathrm{ii}}$, ocorridos provavelmente em meados do século XIX, os indígenas se estabeleceram às margens do Rio Catuléiii - afluente do Rio Pardo. No entanto, a presença dos Mongoió em toda a região Sudoeste da Bahia já havia ganhado notoriedade desde o século XVI com os primeiros registros efetuados pelos entradistas Francisco Bruzza Espinosa e o Padre Jesuíta João de Azpilcueta Navarro (Cartas Avulsas dos Jesuítas, 1933).

A cidade de Itapetinga (Itatinga), atualmente faz parte do Território de Identidade Médio Sudoeste da Bahia $^{\text {iv }}$, possuindo em 2010 uma população estimada em 68.273 mil 
habitantes, como mostrou os dados do censo do Instituto Brasileiro de Geografia e Estatística (IBGE, 2010). Conhecer essa cidade dentro dos capitais culturais e sociais somente foi possível pelos seis anos de nossas investigações. Dessa maneira, durante o tempo do mestrado $^{\mathrm{v}}$ e do doutorado ${ }^{\mathrm{vi}}$, acabamos por analisar as questões educacionais, culturais, econômicas e religiosas que desencadearam a história e a constituição social de Itapetinga.

A dissertação ao trazer as representações que foram construídas pelos moradores da cidade de Itapetinga a partir da inclusão da Universidade Estadual do Sudoeste da Bahia (UESB), em seu território, mostrou um período marcado por lutas e reivindicações, cujos embates, originaram mobilizações simbólicas. A partir da ideia de que a representação se constitui em uma matriz de percepção/ação, objetividade/subjetividade que no campo social exerce influência mútua entre sujeitos e objetos, esse estudo adotou como um de seus procedimentos metodológicos: a história de vida. Foi assim que em um depoimento tivemos pela primeira o conhecimento que, aquele território, era habitado por nativos tidos como “selvagem" e "sem sabedoria", ou seja, não havia o respeito às culturas diferenciadas.

Quando chegamos ao doutoramento, agora já trabalhando com as memórias dos moradores de Itapetinga, mesmo tendo como foco o campo religioso itapetinguense, que em seu processo de urbanização foi incorporada através das representações dos batistas. Dito em outras palavras, a cidade possui uma distinção em relação a maioria de outras áreas urbanas do Brasil, já que se encontra em sua principal praça comercial a edificação de uma Igreja Batista. Foi em torno desses dois símbolos (praça e igreja) que ocorreu o nascimento e o crescimento da cidade de Itapetinga.

A Praça e a Igreja são simbologias tão marcantes no imaginário do povo brasileiro que quando se conhece uma nova cidade, principalmente quando essa é pequena, não é raro que a sua descrição seja pela referência: "no centro tem uma praça com uma igreja". Narrador e ouvinte não mencionam e nem interessam em falar que tipo de Igreja é, pois, fica subentendido que provavelmente, trata-se de uma Igreja Católica. Essa visão incorporada por representações, tem uma imagem psíquica fortemente relacionada segundo Teixeira (2001a) e Murilo Marx (1980) a dois motivos: a composição e a concepção de cidade marcadamente herdada da colonização portuguesa.

As praças cívicas e religiosas brasileiras de acordo com Teixeira (2001b), mesmo que não tenha sido uma transposição fidedigna do modelo urbano português, mas sim, uma 


\section{REPRESENTAÇÕES DOS MORADORES DA CIDADE DE ITAPETINGA-BA}

adaptação às novas condições da Colônia, trouxe valorações para esses espaços como mecanismos de consolidação dos aspectos estéticos, simbólicos e funcionais. Corrobora com esse pensamento o Murilo Marx (1980), ao trazer a ideia que no Brasil era entorno da praça religiosa católica que se edificavam as residências mais suntuosas, os imóveis públicos e o comércio. A praça religiosa, além de manter o convívio entre as diferentes pessoas do local, também servia como um elo de estreitamento das relações da paróquia com os seus adeptos. "Uma igreja, uma praça; regra geral nas nossas povoações” (MARX, 1980, p.54), ao se concretizar no desenvolvimento urbano do Brasil, se transformou em símbolo de manutenção do poder religioso, instalado no núcleo social da cidade.

Partindo deste ponto de vista, a cidade de Itapetinga herdou tanto a composição das praças cívicas quanto das praças religiosas. Todavia, o núcleo central e inicial da cidade abriga uma Igreja Batista (MOREIRA, 2009; CAMPOS, 2006). Ao investigar a influência cultural da Religião Batista sobre a cidade de Itapetinga foi possível perceber que essa tradição religiosa se transformou muitas vezes. Assim, fosse perdendo ou incorporando novos aspectos, foram a ela somada mais outras trinta igrejas de origem protestante. Somente para lembrar, Lévi-Strauss (1973, p. 333) já dizia da "bricolagem”, mostrado que a cultura advém de um "fenômeno natural, resultante das relações diretas ou indiretas entre as sociedades". Isto significa, que uma cidade em seus desdobramentos cotidianos tem muito mais teias se imbricando que não podem ser analisadas apenas através da codificação de uma linha histórica linear, muito menos, apenas através de decodificações estatísticas, como coordenadas geográficas, número de habitantes, tamanho de área e localização.

Nesse sentido, são os aspectos sociais, permeados em torno das diferenças entre as etnias e as crenças religiosas da cidade de Itapetinga que chamaram a nossa atenção, ainda mais, se for tomado a construção da religião como uma representação, que em sua influência cultural conduz a uma socialização, através da "incorporação dos habitus de classe, que produz a filiação de classe dos indivíduos, reproduzindo ao mesmo tempo a classe enquanto grupo que compartilha o mesmo habitus" (BONNEWITZ, 2003, p.75). Logo, a religião passa a ser considerada como uma área de conhecimento em constante diálogo com o mundo, como referenda Bourdieu (2004), uma construção que possui uma estrutura social e uma estrutura simbólica.

A partir dessas reflexões, deve se evitar um dos erros mais comuns encontrados quando se analisa a contextualização religiosa, vislumbrá-la apenas dentro de uma conjuntura 
teológica ou histórica. O campo religioso possui em si mesmo um corpo simbólico de domínio no interior dos grupos sociais capaz de determinar a "legitimação de todas as propriedades características que formam os estilos de vida" (BOURDIEU, 2007a, p.35). Por essa razão o campo religioso, além de provocar a criação de imagens, norteia as ações cotidianas dos indivíduos, formando a memória grupal.

É dentro dessa memória que forma a valorização dos aspectos sociais e econômicos; ou então, dos espaços públicos, como ocorre com a atual Praça Augusto de Carvalho (antiga Praça Castro Alves). Afinal, esse foi o espaço embrião, que naquele início do século XX serviu como marco histórico para a formação de Itapetinga; ponto para a circulação de transeuntes; local que abrigou as movimentações migratórias dos homens, das mulheres e das crianças que se transformaram nos novos moradores da cidade; espaço central que presenciou a chegada dos batistas ao se aventurarem, em um território dominado pela Religião Católica Romana, apropriando de fiéis e provocando no decorrer do processo de urbanização da cidade, exatamente naquela praça, a criação de uma Igreja Batista; mas também, foi nessa praça que pelos trechos da memória do Senhor Jovino Francisco de Souza ${ }^{\text {vii }}$, presenciou o triste fim do povo Mongoió que ainda se fazia presente na terra itapetinguense. Pois ali, como traz em suas memórias, o Senhor Juvino viu amarrado dois adolescentes indígenas, que eram tratados dessa forma para servir como exemplo a população.

E foi a partir da memória do Senhor Jovino Francisco de Souza que buscamos a sinalização da existência do povo Mongoió dentro da área geográfica da cidade. Para tal foi preciso conhecer aquilo que aqui será conceituado como a "pré-história de Itapetinga". Contudo, como a pré-história de Itapetinga está ligada aos municípios de Vitória da Conquista e Itambé, foi observado que no senso comum dos moradores da cidade, circula a ideia que se houve uma ancestralidade do povo Mongoió dentro da região, não foi exatamente no núcleo que formou a área urbana de Itapetinga. Esse fato nos levou a averiguar os condicionamentos históricos e sociais para a negação da presença do povo Mongoió dentro do território itapetinguense.

Essa negação a priori, já tem uma primeira constatação, que foi aflorada exatamente ao se iniciar a coleta do material sobre a existência indígena dentro do território de Itapetinga, pois, não foi encontrado e não existe nenhuma fonte documental incluso em seus órgãos públicos que trate sobre o tema. Assim, foi através da "memória dos velhos" (BOSI, 2010, 
p.36), o único caminho para conhecermos as particularidades de uma época, que apenas a memória de quem viveu a história pôde nos apresentar.

Foram eles, como diz Bernardo (2007, p.31), "os paisagistas da história”, os primeiros a rir, a chorar, a lastimar, enfim, os primeiros a viver os dissabores, mas também, as alegrias que se constituíram na história da cidade. Foram eles os primeiros a conhecer o povoado quando ainda era formado pelas matas virgens, por seus rios caudalosos, suas estradas sendo formadas, enfim, foram eles os primeiros a conhecer as suas ruas, casas, bairros e igrejas.

Portanto, foi através da pesquisa qualitativa, tendo como instrumento metodológico a memória dos velhos de Itapetinga, a pesquisa em documentos, cartas e registros antigos o caminho que nos possibilitou verificar que antes da formação dos processos urbanísticos, do desenvolvimento social e econômico da cidade, ou mesmo, como foi constituído e consolidado o seu campo religioso, já existia um passado que ainda cabe ser lembrado e recuperado. Tal afirmativa, além de justificar a discussão aqui tratada, também nos impulsiona a trazer para o debate aquilo que ainda está escondido na história social da cidade.

\section{Da Terra Mongoió a Criação do Povoado da Pedra Branca}

Foi a chegada daqueles conhecidos pela memória da população de Itapetinga como "os pioneiros": Bernardino Francisco de Souza, seu irmão Tercílio Francisco de Souza e sogro Possidônio Antônio de Carvalho que, com alguns trabalhadores em 1912, adentraram as matas da região do Sudoeste da Bahia, abrindo uma pequena clareira à beira do leito do rio Catulé, marcando o prenúncio do núcleo urbano de Itapetinga. As condições eram péssimas "para trafegar pelas densas florestas fechadas, o que dificultava a locomoção humana, fosse por rodovias, em lombo de animais, ou até mesmo quando os interessados se aventuravam a enfrentar longas distâncias a pé” (GOMES, 2006, p.11).

Para além da história linear e descritiva de Gomes (2002), o advogado Campos (2006) verificou em uma correspondência de Bernardino Francisco de Souza o seguinte relato: quando chegou às margens do Rio Catulé Grande foi ao acaso, encontrou muitos animais selvagens, muita mata nativa e uma infinidade de caboclos (chamados na época de índios ou nativos) que disputavam a governança das margens do rio. Os "índios", mesmo não demonstrando nenhum tipo de aversão, muitas vezes, até mesmo os presenteando com caças e pescas, não eram fáceis de se lidar, não era raro o fato de furtarem ferramentas, especialmente 
facões e machados. "Os índios viviam assombrados, para cima e para baixo [Serra Couro D' Anta] com medo do homem branco" (CAMPOS, 2006, p.68).

Bem antes dessa época, ainda nos anos de 1817, já havia nesta região uma grande Fazenda que fora registrada no nome "de Bernardo Lopes Moitinho, doada pela metrópole portuguesa, por ele ter aberto a estrada que ligava o sertão ao litoral. A propriedade se chamava Onça $^{\text {viii” }}$ (CAMPOS, 2006, p.54). Nesta fazenda tinha um pequeno povoado que, mesmo sendo atualmente extinto era na época, segundo Campos (2006), muito conhecido em toda a região.

A passagem descrita pelo historiador pode ser verificada na memória da Senhora Terezinha Ribeiro $^{\text {ix }}$ quando recorda que ela e toda a sua geração familiar ancestral havia nascido na Fazenda Onça antes de ir morar definitivamente em Itapetinga. Pelo que nos contou, a Fazenda Onça era famosa por suas festas e encontros religiosos de origem católicos. Além disso, como recordou a Senhora Terezinha Ribeiro, a Fazenda Onça servia de abrigo para tropeiros, boiadeiros e mascates que cruzavam a região. Isto fazia com que toda a área, inclusive a que Bernardino Francisco de Souza tomou como sua e que, futuramente venderia para Augusto de Carvalho, responsável por formar o pequeno povoado de Itatinga, fosse muito conhecida por todos que trafegavam pela região. Isto torna impossível (supomos) que, de fato, Bernardino, como assegura Campos (2006), neto de "índio" ou "caboclo" (popularmente chamado) como era, não soubesse de antemão que aquela área pertencia por direito ao povo Mongoió.

Como em muitas outras formações das cidades brasileiras, a área de Itapetinga foi marcada por práticas agressivas da exploração da natureza. Mediante, podemos verificar que em sua pré-história a região foi habitada pelo povo Mongoió, facilmente sendo comprovado na pesquisa de Wied-Neuwied (1942) e nas descrições do Padre Azpilcueta (1933). Entretanto, isto não seria nenhuma novidade se tratando da história do Brasil. Assim, O que queremos provar é que até mesmo quando Augusto de Carvalho, que no mês de setembro, dia desconhecido por todos, no ano de "1924, separou dentro da mata bruta um pedaço de terra de 10 hectare (ha), para a formação do povoado" (OLIVEIRA, 2003, p.54), decidindo chamar pelo nome de Itatinga, cujo significado, no idioma Tupi, traduz- se por "pedra branca", ainda havia os indígenas que residiam no território. 
Para tal, cabe levantar alguns dados históricos que principiam pela descrição de Jabur (1998) e Campos (2006), quando afirmam que ainda na época de Bernardino, Augusto de Carvalho tirou dentro da mata bruta a sua primeira posse, começando a expandir as suas propriedades. Foi Augusto de Carvalho quem apresentou à região de Itapetinga ao seu colega de profissão, o comerciante de gado pé duro (boi que não é de raça) e fumo de corda que se chamava: Alfredo Antônio Dutra. Este seguindo o modelo e a indicação do amigo tirou uma posse às margens do Rio Catulé Grande iniciando a história da Fazenda Liberdade. Também, acabou por demarcar um trecho de terra nas proximidades da Serra Couro D’Anta, onde ainda viviam a família Mongoió. Um dia,

\begin{abstract}
Alfredo Antônio Dutra, no final de 1935, atraiu os índios deixando-os caçar em suas roças, colher milho, mandioca, cana de açúcar, assim pegou alguns deles da Serra do Couro D' Anta, para a roça de sua Fazenda Itaporanga, vestiu-os e os trouxe para a praça, para ter contato com a comunidade [...] logo depois foram enviados para Itaju do Colônia, onde havia um posto para os índios se adaptarem a civilização (JABUR, 1998, p.44).
\end{abstract}

Ou seja, onde "gentilmente", Alfredo Antônio Dutra permitiu aos nativos fazer a retirada dos alimentos, havia sido em outros tempos as suas próprias terras de cultivo. Essa fala de Jabur (1998) foi crucial para comprovar que houve a presença dos indígenas dentro do território urbano de Itapetinga. Tal afirmação pode ser reverenciada pelos trechos da memória do Senhor Jovino Francisco de Souza ao recordar que:

Quando era bem jovem, morava na Rua Boa Nova e, quando escapulia, ia
para a Praça, que hoje é a Praça Augusto de Carvalho, ali na esquina tinha
uma lanchonete que se chamava Maringá. Eu fui surpreendido, um dia, com
algo inusitado; naquele momento, a rua não tinha muitos moradores, não
tinha muita gente, até porque estamos falando de um lugar que era muito
pequeno, foi quando me deparei com dois garotos amarrados a um pedaço de
madeira que parecia um poste, com vestimentas estranhas e gritando sem
parar. Perguntei do que se tratava e a pessoa respondeu: “- Isto é índio"!
Porque eles tinham que amarrar aqueles dois garotos bem no meio da praça,
mas, aquilo era algo comum por aqui.

O povo Mongoió foi sacrificado no mesmo espaço onde mais tarde se construiu a Igreja Batista. Por não aceitar as normas sociais trazidas para a região pelo "homem branco" sofriam agressões físicas e psicológicas como demonstrativos de exemplos de condutas dentro do povoado. De tal modo, ratifica claramente que a noção desta provável e vindoura civilização não cabia ao nativo da região. Pois como mostrou Jabur (1998), não havia respeito aos trajes indígenas que para frequentar a Praça precisava se "fantasiar" com as roupas do "homem 
branco"; não havia respeito aos costumes dos Mongoió, já que não se adaptaram a esse novo mundo, foram enviados para um centro de catequese que funcionava em Itaju do Colônia, para "ser preparado para a civilização". Ou seja,

[...] foi com o objetivo de conquistar os índios, que o governo brasileiro iniciou uma campanha no sentido do aldeamento dos gentios, usando, principalmente, missionários católicos. Nesse sentido, a partir de 1844 começaram essas atividades. Tanto que uma ação missionária é fundada na Barra do Rio Catulé, margem do Rio Pardo, inicialmente chefiada pelo Frei Ludovico de Livorno, italiano, mas substituído pelo Frei Luiz de Grava. Os índios aldeados, cerca de 125 , plantavam mandioca e outros produtos de subsistência. Talvez tenha sido a primeira povoação do território correspondente ao atual município de Itapetinga. Pena que tal povoação não durou muito tempo. Hoje, quem vai ao local não constata nenhum vestígio dessa povoação (CAMPOS, 2006, p.51).

A perda da terra e o confinamento dentro das colônias foi a extensa penalidade que os indígenas de Itapetinga começaram a sofrer no transcorrer do transformar de sua cultura. Senhor Jovino Francisco de Souza revela ainda que:

Fiquei observando e acredito que quem estava na rua, também, observava aquilo, sabendo que eram adolescentes. Ficou marcado em minha memória, me impressionou a fisionomia deles, era de espanto e de medo. Aquilo me marcou tão profundamente que nunca tive coragem de perguntar para minha mãe, pouquíssimas vezes ventilei este fato. Hoje, pergunto, o que fizeram com os índios daqui? Não conheço na história de Itapetinga um Índio que tenha sido domesticado. Alguém disse, certa vez, que aqueles índios não habitavam nesta região, que apenas passavam por ela. Eu não acredito nisso, eles habitavam aqui sim, tanto, que aquelas crianças amarradas não estavam aqui de passagem. E estavam ali amarrados na praça para ser visto pelo povo. Mas isso era comum, ninguém sabia quem fazia? Todo mundo sabia que eram as autoridades, que era a polícia.... Essa é uma das coisas que mais me impressionou e impressiona, até hoje, emociono-me toda vez que me lembro daqueles garotos amarrados.

Consequentemente, com a chegada do homem "branco" essa foi a última notícia do povo Mongoió na região Itapetinguense. Assim,

[...] o mar verdejante da mata foi bólido, e surgiu a primeira ilha de derrubada. Os índios sentiram a presença de estranhos nos seus domínios, os bichos das matas perceberam a presença do invasor, nos rios, antas, capivaras e lontras ouviram e sentiram o troar das espingardas. Acordava a região, o toque desbravador do homem e a área de Itapetinga começavam a ser integrada ao mundo "civilizado". Caçadores, viajantes e jagunços tinham dado notícias desta região onde andaram: - A terra era boa, que as elevações 
eram pequenas, que os rios constantes garantiriam a vida de quem dessas áreas se apossassem (NERY. 1995, p.101).

Tal discurso revela o desbravamento da nova terra e, como nesse local, em suas origens sucedeu o uso de práticas agressivas da exploração da natureza e da força das armas diante dos nativos ${ }^{\mathrm{x}}$ que ali habitavam. Nestas passagens, o que ocorreu foi o equívoco ${ }^{\mathrm{xi}}$ existente dentro da própria estrutura histórica da modernidade, herdada principalmente, a partir da colonização europeia. Tanto que, para aqueles que chegavam a região de Itapetinga, os nativos locais eram tidos como "selvagem" e "sem sabedoria". Não havia o respeito às culturas diferenciadas e tal concepção etnocêntrica, aos poucos expulsou os indígenas, substituindo a representação cultural da região.

Naquele tempo era tudo diferente, mais bonito, todos eram amigos de todos.... Cortei a primeira árvore dessa terra para construir o barraco, mas aqui era índio para todo lado, eles eram como os bichos, bem selvagens, às vezes era preciso bronquear com eles, resistir até que tentaram, mas a gente dava um jeito neles. (risos). Depois, ah! De alguma forma, foram sumindo, sumindo, até que um dia sumiram de verdade e, ninguém mais ouviu falar deles, e aqui brotou o pasto da comunidade pecuarista ( ${ }^{\text {xii. }}$ 2008)!

A resistência dos nativos aos poucos foi sendo substituída, por um novo costume, que trazia como promessa transformar a terra encontrada, em um novo mundo civilizado. Nesse relato de B tem outro ponto importante: o saudosismo, com isso demonstra o quanto ainda é presente em sua memória, as representações dos fatos passados da Itapetinga nascente.

Quando B diz que "antes todos se conheciam, todos eram amigos", tal comentário ocorre por um motivo latente, a cidade também, atualmente se encontra em um universo de transformações sociais. Para Bauman (2003), os homens mantêm relações tensas e paradoxais, entre as ideias e o que de fato é uma comunidade. Vivendo entre o desejo da segurança ofertada e a liberdade, o homem sabe que a comunidade existente, quando doa a proteção é dura e exige troca para todos os serviços que possam ser ofertados. Por isso, fazer parte de uma comunidade, no sentido dado por Bauman (2003), é saber que ela, como agrupamento humano, possui formas consideradas de mecanismos para a dominação das relações e das produções sociais.

Os grupos sociais vitimados pela modernidade capitalista, tornou-se mais "consumidores, fluidos, líquidos e desregulamentados", onde o "desengajamento" convive lado a lado, com o "excesso", que, 
[...] em verdade, como diria Bourdieu mais tarde, a tentação e a sedução acabaram substituindo a regulação normativa e a vigilância ostensiva como principais meios de construção do sistema e de integração social. O principal efeito da tentação e a essência da sedução é a ruptura da norma (ou antes, a transcendência perpétua da norma, com uma pressa que nega aos hábitos o tempo de que precisam para fixar-se em normas). E na ausência da norma, o excesso é a única esperança da vida. Numa sociedade de produtores, o excesso era equivalente ao desperdício e por isso rejeitado e condenado; mas nasceu como uma luta da vida com a norma (uma doença terminal, como se sabe). Num mundo desprovido de normas, o excesso deixou de ser um veneno e tornou-se o remédio para as doenças da vida; talvez o único apoio disponível. O excesso, esse inimigo declarado da norma, se tornou a própria norma; talvez a única norma. Certamente uma norma curiosa, que escapa à definição. Tendo rompido as algemas normativas, o excesso perdeu seu sentido. Nada é excessivo se o excesso é a norma (BAUMAN. 2003, p.118)

Essa situação, balizadora dessa cultura presente na vida das pessoas traz o medo e angústia, mas também, são construtores de novos caminhos. O que significa para Bourdieu (2007b), que as formas que se solidificam no senso comum, ocorrem, a partir do poder deliberado pela cultura. Cenário, onde o habitus pode ser utilizado para compreender como que as representações, interferem diretamente na construção dos estilos de vida em um espaço social.

Ao criar os antagonismos, mas também, as similaridades se encontra a construção de uma memória das quais as narrativas oficiais não relataram, mas também existem outras tantas que foram documentadas e registradas, como aquela que se refere ao fato de que a partir de 1912, quando outros companheiros de Bernardino - que já tinha a posse da terra ao qual tinha dado o nome de Fazenda Astrolina - também, vieram para o novo local, ali se instalaram. Entre estes desbravadores, pode se enfatizar a chegada de Augusto Andrade de Carvalho (1892/1956), que além da terra que marcou como sua, ainda, comprou a Fazenda Astrolina e desta: "em 1923, separou dentro da mata bruta um pedaço de terra de 10 ha. para a formação do povoado.” (OLIVEIRA. N. 2003, p.54).

Foi assim que se formou Itapetinga, no início batizada por Itatinga ${ }^{\text {xiii. }}$, possuía apenas cinco casas de taipa. Conta Oliveira (2003) que o objetivo do fundador era concentrar na área o abastecimento de alimentos que pudessem suprir a necessidade daqueles que trafegavam a pé ou no lombo de jumentos e cavalos. Surgem então, ritmos de trabalho e cultura que marcavam o "habitus" (re)produtor da nova definição social. Dois anos mais tarde, Itatinga 
possuía quarenta casas registradas e, cerca de mil habitantes, sendo elevada à condição de Vila $^{\text {xiv }}$, que aconteceu devido à condição da terra para o desenvolvimento agropastoril, cujo desenvolvimento da prática econômica estava se tornando notório (GOMES, 2002).

Esse é o prenúncio da substituição da mata fechada por um centro mais urbano. Tais notícias espalhadas pelo território baiano, transformou Itapetinga em herdeira da produção pecuarista que havia sido iniciada na Região da Ressaca (cidade de Vitória da Conquista) no final do século XVIII.

\section{Representação Mongoió e a (Pré)História Itapetinguense}

Mesmo diante do quadro desenhado dentro do jogo social, no qual vivem os moradores de Itapetinga, inegavelmente, ela é o resultado de um projeto deslumbrante aberto por aqueles que construíram a sua história, pois, foram os seus pioneiros que enfrentaram muitas dificuldades por dentro da mata fechada para chegar aquilo que foi considerado como o embrião da cidade (Praça Augusto de Carvalho). Mas, não podemos considerar esse ponto, como limitador para as demarcações históricas e geográficas da história social da cidade de Itapetinga, pois, houve um período antecedente a vinda de Bernardino Francisco de Souza e mais tarde do fundador Augusto de Carvalho, chamada pelo historiador Emerson Campos de "pré-história", cujo ponto de partida foi

[...] o Século XVI, mais precisamente em 1553, quando a coroa portuguesa contratou o entradista Francisco Bruzza Espinosa de nacionalidade espanhola. Esse, avançou as terras do atual noroeste mineiro e retornou a costa da capitania dos Ilhéus, seguindo sempre os cursos do rio grande (atual Jequitinhonha) e do rio da Ourinas - posteriormente rio Patipe e atual rio Pardo (CAMPOS, 2006, p.17).

Junto com o espanhol se encontrava João de Navarro, padre jesuíta de origem nobre da Casa dos Azpilcueta, cuja ascendência pertencia ao reino de Navarra - localizado ao norte da Península Ibérica -, que era reconhecido por ter sido um dos núcleos da resistência cristã frente ao domínio islâmico no período medievo. O Padre havia chegado ao Brasil acompanhado do padre Manoel da Nóbrega, Leonardo Nunes, Antônio Pires e os irmãos Diogo Jacomé e Vicente Rodrigues. O grupo fazia parte da primeira missão jesuítica que, 
junto ao Governador Geral Tomé de Souza, adentraram a terra Brasil em 29 de março de $1549^{\mathrm{xv}}$.

1549, chegam ao Brasil em 29 de março o $1^{\circ}$ Governador Geral Thomé de Souza e a I a Missão de Jesuítas [Nóbrega, "Cartas" I, "Cartas Avulsas", I] composta dos Padres Manoel da Nóbrega, João de Azpilcueta Navarro, Leonardo Nunes, Antônio Pires e Irmãos Diogo Jacomé e Vicente Rodrigues [Anchieta, Informações, páginas 13-4], Leonardo Nunes e Diogo Jacomé enviados aos Ilheós e Porto-Seguro [Nóbrega. Cart. I]. Navarro e Pires nas aldêas da Bahia [Nóbrega. Cart. III - [sic] (Cartas Avulsas, 1933, p.20).

Considerado, dentre os Jesuítas, como o primeiro mestre e tradutor dos idiomas nativos (Tupi e Guarani) encontrados no litoral, o padre João de Azpilcueta Navarro morreu no dia 30 de abril de 1557 na Bahia ${ }^{\text {xvi }}$, mas, antes, deixou traduzidos orações e sermões que foram facilitadores para o trabalho de catequização dos nativos de Pindorama ${ }^{x v i i}$. Nos fragmentos abaixo foram destacados alguns trechos da Carta escrita pelo jesuíta em Porto Seguro, exatamente em um dia que, no futuro, permaneceria na memória viva do nordestino brasileiro, pois, foi aquele destinado a homenagear ao São João (24 de junho de 1555); ali o padre narra a viagem que o levou a passar pela região onde atualmente está localizada a cidade de Itapetinga.

Caríssimos irmãos, passa de ano e meio que, por mandado do nosso padre Manoel da Nóbrega, ando em companhia de doze homens Christãos, que, por mandado do Capitão, entraram pela terra dentro a descobrir si havia alguma nação de mais qualidade, [...] entrámos pô-la terra dentro 350 léguas, sempre por caminhos pouco descobertos, por serras mui fragosas que não tem conto, e tantos rios que em partes, no espaço de quatro ou cinco léguas, passamos cinquenta vezes contadas por água, e muitas vezes, si me não socorreram, me houvera afogado. [...] os índios andavam pintados com tintas, ainda nos rostos, e emplumados de penas de diversas cores, bailando e fazendo muitos gestos, torcendo as bocas e dando uivos como perros: [...]. No outro dia fomos e passamos em muitos locais despovoados, [...]. Neste ermo passamos uma serra mui grande, que corre do Norte para o meio-dia, e nela achamos rochas mui altas de pedra mármore. Desta serra nascem muitos rios caudais: dois deles passamos que vão sair ao mar entre Porto Seguro e os Ilheós: chama-se um rio Grande, e o outro rio das Ourinas. [...] os tempos são mui temperados, fora de alguns anos secos. Ha muita caça, assim de animais como de aves: há uns animais que se chamam antas, pouco menores que mulas, e parecem-se com elas, senão que têm os pés como de boi [sic] (AZPILCUETA, 1933, p.147-150). 
Sobre os aspectos trazidos pelas Cartas Avulsas, Campos (2006, p. 18) nos confirma

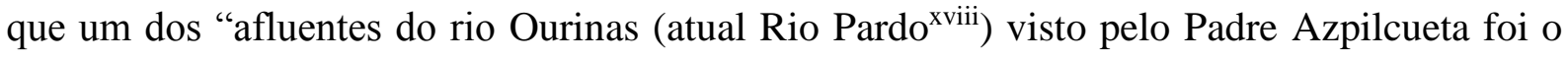
Rio Catulé”, água que banha a cidade de Itapetinga. Outro ponto da carta do padre que merece registro é quando faz a narrativa sobre índios e antas - antigos habitantes da região onde está localizada a cidade de Itapetinga. Foram eles, os nativos e os animais, os principais representantes do sacrifício para solidificar o cristianismo desejado pelo Padre quando profetizou: "O fructo sólido desta terra parece que será quando se for povoando de Christãos. Nosso Senhor por sua misericórdia saque estes miseráveis das abominações em que estão [sic]" (AZPILCUETA, 1933, p.150).

O primeiro contato do homem branco na atual região Sudoeste da Bahia, espaço que se transformaria na cidade de Itapetinga, foi direcionado pelos padrões cristãos jesuíticos, mas, naquele momento o que Azpilcueta (1933) não poderia prevê era que a cultura dos valores cristãos arraigados no local, pelo menos no início do século $\mathrm{XX}$, seria de ordem protestante, fortemente marcada pela presença dos fazendeiros batistas na região.

\section{Os Bandeirantes e o fim da Cultura Mongoió}

Alguns séculos antes da consagração cristã, chegaram a região Sudoeste da Bahia os bandeirantes, estavam eles destinados a buscar o ouro ou quaisquer riquezas que pudessem ser encontradas nessa área territorial. Sobre esse aspecto, Campos (2006, p. 18-19) assevera que conhecer a "origem da expansão do ciclo colonizador lusitano na formação do núcleo populacional da Vila da Conquista"xix , fundada no final do século XVIII pelo "sertanista João Gonçalves da Costa", como também, a história do nascimento e desenvolvimento da cidade de Itambé, fornece uma melhor compreensão sobre a própria formação histórica e social da cidade de Itapetinga, afinal, o seu território inicialmente esteve oficialmente ligado a estes dois municípios.

Tudo começou em meados do século XVIII, quando um ex. escravo português que se encontrava no Norte de Minas Gerais, ao compor o grupo de bandeirantes com os homens brancos, partiram das Minas Novas com direção à Bahia. Nascido, provavelmente, por volta “de 1720, na cidade de Chaves, em Trás-os-Montes (Portugal), o preto forro João Gonçalves da Costa envolveu-se no processo de conquistar os sertões" (IVO, 2009, p.14). Assim, ao adentrarem 
[...] as regiões não litorâneas, inseriram os sertões no movimento planetário das monarquias católicas: entre eles, o Sertão de Minas Novas do Araçuaí; o Sertão da Ressaca, grosso modo, Município da Imperial Vila da Vitória; o Alto Sertão da Bahia, Rio de Contas e Caetité. O sertão do rio Doce e o sertão do rio São Mateus foram os cenários das aventuras e conquistas do superintendente das Minas, Pedro Leolino Mariz, do mestre-de-campo João da Silva Guimarães e do ex escravo português, o capitão-mor da Conquista, João Gonçalves da Costa (IVO, 2009, p.29).

Campos (2006, p.30), por um lado, concorda com Ivo (2009) quando diz que a Vila da Conquista foi fundada pelo ex escravo português João Gonçalves da Costa, com o interesse relacionado à procura do ouro extinto nas Minas Gerais, por outro lado, Campos (2006), ainda afirma, que havia também, o empenho de Portugal em criar um aglomerado urbano entre a região litorânea e o interior do sertão brasileiro. Foi assim, que o lugar conhecido como o Sertão da Ressaca, berço da atual cidade de Vitória da Conquista, entraria para o mapa da história.

Essa região, que inicialmente, se limitou à produção da atividade pecuarista era habitada dentre outros grupos indígenas pelo povo conhecido como Mongoió, família indígena que pertencia ao tronco linguístico Macro-Jê. Atualmente, como esclarece Cruz e Corozomae $(2015)^{\mathrm{xx}}$ essa família linguística se encontra em revitalização em algumas regiões do Brasil. Quando se trata do passado, entre os anos de 1815 a 1817, o botânico e Príncipe Maximiliano Wied-Neuwied da Renânia, localizada no oeste da Alemanha, em sua narrativa sobre a "Viagem ao Brasil"xxi descreve que havia um

[...] grupo de índios Camacã, descendentes de uma tribo que os portugueses conhecem com o nome de "Mongoió". Esses índios só se estendem ao sul até o Rio Pardo [...] Somente aqui, no "sertão" da Capitania da Bahia, pode-se ainda observá-los em seu estado primitivo, pois muitos deles nunca viram um europeu (WIED-NEUWIED, 1942, p.341).

Continua narrando Maximiliano que o vocabulário dos “Camacã ou Mongoió" da capitania da Bahia era uma língua muito singular, cheia de palavras bárbaras e extensas, com muitos sons guturais. O final das palavras era sempre pronunciado de um modo breve e indefinível. Para Wied-Neuwied (1942, p.341), os sons emitidos pelo povo Mongoió pareciam nasais, palatais e guturais a um só tempo, usando em abundância as letras ch, k e ä. No entanto, se Wied-Neuwied percebeu, em sua viagem, que haviam diferentes línguas que eram faladas pelos indígenas, o que deveria ser visto como uma variedade cultural, foi 
considerada, por ele, como um fator de maior ou menor desenvolvimento da civilização dos nativos.

Dessa maneira, de acordo com o botânico, o povo Mongoió que vivia na Região da Ressaca, à beira do rio Catulé Grande ${ }^{x x i i}$, estava longe de ser considerado como civilizado, já que a sua comunicação verbal não passava de um prenúncio do desenvolvimento linguístico. Além disso, chamou a atenção para o fato que o povo Mongoió possuía costumes e ritos religiosos que eram particulares, mesmo sendo considerado como "primitivos eram mais civilizados que seus vizinhos formados pelas tribos do povo Pataxó e Botocudo; não viviam mais exclusivamente da caça, pois, já cultivavam as plantas" (WIED-NEUWIED, 1942, p.341).

O povo que era chamado pelos portugueses de "Mongoió" e definido por WiedNeuwied (1942) por “Camacã (ou Kamakan)”, era habituado em se fixar em uma determinada área, utilizando-a para a sua sobrevivência; nesses espaços faziam o plantio de ervas e de algumas raízes. Tinha por tradição depilar o corpo e ornamentá-lo com penas de aves. Na aldeia o trabalho era dividido de acordo com o gênero; os homens praticavam a caça e a agricultura. Cabia, às mulheres, trabalhar com as tecelagens, o que lhes destacava um importante papel, sendo delas a memória construída sobre as formas de arte encontradas nas cerâmicas, bolsas ou sacos de fibras feitos das palmeiras existentes na região.

Além disso, pela ótica de Wied-Neuwied (1942), o povo Mongoió, por viver e fixar em áreas onde plantavam, era considerado diferente de outros povos indígenas nômades. As diferenças provocavam guerras entre os nativos, cuja disputa nascia do desejo em proteger o espaço de caça e de pesca. Este motivo sinalizou para Ivo (2009) em sua pesquisa, que foi a rivalidade entre os nativos a principal causa na região da Ressaca para produzir um acordo entre o povo Mongoió e João Gonçalves da Costa. No entanto, Costa

[...] que foi descrito como preto-forro, em 1744, em carta "patente do posto de capitão-mor do terço de Henrique Dias", concedida por André de Mello e Castro, conde de Galveas, então "membro do Conselho da Majestade do Rei e capitão de mar e terra do Estado do Brasil". A justificativa da patente esclareceu que o título de capitão é "da gente preta que servirá na conquista e descobrimento do mestre-de-campo João da Silva Guimarães". Nomeado para substituir Guimarães nas conquistas relacionadas às buscas de metais e pedras preciosas, João Gonçalves da Costa acabou por traçar outro destino para suas aventuras: tornou-se proprietário da maior parte das terras do Sertão da Ressaca e, junto com seus filhos e descendentes, passou a 
controlar a vida política da maior parte deste Sertão por quase dois séculos (IVO, 2009, p.14).

O controle da família Costa acabou com a paz entre os colonizadores e o povo Mongoió, atingindo o ápice quando os nativos perceberam que estavam "sendo escravizados pelo homem branco" (IVO, 2009, p.15). A consequência foi uma guerra sangrenta ${ }^{x x i i i}$. Sobre esse aspecto, utilizando os dados da Enciclopédia dos Municípios Brasileiros de 1958, o historiador Campos faz a seguinte observação: “João Gonçalves da Costa, após a guerra contra os índios em que saiu vencedor, cumprindo promessa edificou uma capela em louvor a Nossa Senhora da Vitória, no local do último combate com os gentios” (2006, p. 123). Ivo diz ainda que,

[...] Costa assimilou o universo católico português e se tornou seu defensor no Sertão da Ressaca. Logo após a conquista da região, ergueu uma capela em nome de Nossa Senhora das Vitórias, conforme registra a memória popular da cidade até os dias atuais e no decorrer do século XVIII, sua militância religiosa foi contínua (2005, p.5).

Quando a "Villa da Victória"xxiv se transformou em cidade da Conquista possuía, em seu território, dezesseis (16) distritos, o que incluía o território de Itapetinga. Tomando como critério que o português da região, Capitão Mor João Gonçalves da Costa, era um católico devoto e se transformou no "doutor coronel" como era chamado pelos vaqueiros e até fazendeiros da região, fica previsível afirmar que, a partir dele, houve um maior domínio da Igreja Católica Romana que havia sido iniciado desde o século XVI, ainda no tempo dos primeiros entradistas.

A troca da força bruta pela força ideológica da crença religiosa de origem católica, estabeleceu um campo de manipulação simbólica marcando, aos poucos a vida prática na Região da Ressaca; paulatinamente, foi desenhando um novo estilo de vida. Em Bourdieu (2003) o estilo de vida pode ser caracterizado por um conjunto de gostos respectivamente formados das opiniões políticas, das crenças religiosas, das convicções morais, das preferências éticas ou estéticas, das reflexões filosóficas e dos conhecimentos científicos, como também ligada, em sua natureza prática, às orientações sexuais, preferências alimentares, escolhas de uma específica religião, seleções dos vestuários e prioridades culturais (leituras, escolaridade, alternativas artísticas ou esportivas e etc.). 
Tomando essa referência bourdieusiana em analogia ao povo Mongoió, isto significa que, a partir da chegada do "homem branco" foi perdida a sua cultura, sendo assim, marcada pelas novas configurações dos padrões civilizatórios. Aceitando a mesma menção para a formação social na região, que até então era formada pelas matas virgens, começa a ser percebida a concepção de uma cultura urbana nomeadamente católica. Foi por essa razão, que desde

[...]1851, o diretor-geral de índios, Casemiro de Sena Madureira, apresentou ao Governo um quadro geral dos aldeamentos do Sertão da Ressaca e produziu este texto: "Aldeia do Catulé, a margem do Rio Pardo, conta de índios Camacã, dirigidas pelo missionário Capuchinho Frei Reignero, quase todos ainda mais selvagem são 150. Próxima a essa aldeia há uma horda de indígenas ainda selvagem, que vão se acostumando a catequese empregada pelo dito missionário" (Seção Colonial e Provincial. Série "Índios"; maço 4.611: "aldeias indígenas da Província da Bahia", 1851, Arquivo Público da Bahia). Outro missionário Capuchinho, Frei Antônio de Falerno, também, atuou no Aldeamento da Barra do Catulé, a partir de 1850, ele foi o fundador do posto missionário do lugar, onde havia uma comunidade Camacã, conforme cita o Frei Pietro Vittorino Regni (OFM ${ }^{\mathrm{xxv}}$ - Cap. da obra "Os Capuchinhos na Bahia” Vol. 2, p. 497, 1988). (CAMPOS, 2006, p.51).

Como se vê, "muitas foram as tentativas de domesticar aos índios, aos poucos, na verdade, os selvagens vão se aproximando da civilização. Mas, como não poderia deixar de ser, tudo era feito com muito sacrifício" (CAMPOS, 2006, p.52) dos nativos, que romperam com os seus costumes, suas vestimentas, sua alimentação, seu idioma, seus ritos, enfim, perderam a própria identificação.

Outro lugar que merece evidência no processo pré-histórico de Itapetinga foi a cidade de Itambéxxvi. Campos (2006, p.40-44) destaca que o seu nome foi originado no idioma Tupi, significando "pedra afiada". Itambé, inicialmente, era na região conhecido como o Povoado da Verruga - procedência do nome do rio Verruga, praticamente extinto. O Povoado do Verruga nasceu, provavelmente, entre 1860 a 1890. Naquela época, uma grande seca assolou o sertão baiano e muitas famílias se deslocavam para o litoral em busca de suas sobrevivências. Muitas dessas famílias ficavam pelo caminho, foi assim que os sertanistas Manoel Balbino da Paixão e Manoel Raimundo da Fonseca, de alguma forma negociou com o povo Mongoió, se instalando na região.

Como em Vitória da Conquista, também foi o nativo Mongoió ou Camacã, a formar o conjunto dos primeiros habitantes registrados na pequena Verruga, eles ficavam instalados à margem do Rio Catulé Grande, localizado a cerca de 60 quilômetros ao sul do povoado 
recém-formado ${ }^{\mathrm{xxvii}}$. Portanto, a "pré-história" de Itapetinga, para campos (2006), se finalizou à luz de dois aspectos que cabem ser destacados: Verruga, ao adquirir o status de município, ganhou o nome de Itambé e, por uma questão de divisão territorial do estado da Bahia adquiriu, da cidade de Conquista (agora já produtora de café), a área onde estava situado o pequeno povoado de Itatinga ${ }^{\text {xxviii }}$; e, por ter sido Itambé, distrito de Conquista, ali também, imperava o domínio da tradição católica, que mais uma vez buscava catequizar os nativos que ocupavam aquele espaço.

Tomando como parâmetro os estudos históricos de Ivo (2009) e de Campos (2006), podemos inferir que a raiz religiosa católica de Vitória da Conquista e de Itambé camuflou a face da dominação portuguesa e o aniquilamento paulatino do povo Mongoió. Nesse sentido, o poder é um estado pelo qual uma vontade manifesta do dominador influi sobre os atos dos dominados, basta analisar, que no processo da catequização não havia uma conversão desejada, pois, como aponta o próprio Wied-Neuwied (1942), mesmo aqueles Índios convertidos ao cristianismo romano, somente frequentavam uma Igreja por obrigação, não sendo raro trocar as orações pela arma de fogo.

Isto por que havia uma estreita afinidade entre o poder da Igreja Católica Romana e o Estado de Portugal, muito bem definida por Murillo Marx (2003), quando discute em "Nosso Chão: do sagrado ao profano" a consequência desse legado dentro da colônia brasileira. Para Marx (2003), o parentesco entre a Igreja Católica e o povo brasileiro ganhou forma através das festas públicas, fossem elas sagradas ou profanas ${ }^{\mathrm{xxix}}$, fossem elas nos largos, nas ruas ou nas praças religiosas, acabaram por formar uma relação de proximidade entre o povo e a igreja. Fato que perdurou para além da dominação portuguesa, não sendo raro encontrar, mesmo na formação das jovens cidades, um sentimento de identificação populacional, reservando em suas áreas centrais o lugar destinado para a criação da catedral, igreja, capela ou paróquia de origem romana. É dentro desse legado que começa a ser formado o povoado de Itapetinga.

Assim, a história dos Mongoió narrada por Ivo (2005; 2009) dentro da região do Sertão da Ressaca e por Campos (2006) no território de Itapetinga, ainda acrescida pelas lembranças dos nossos recordadores, nos possibilita sistematizar a seguinte afirmação: primeiro, os índios foram eliminados na área de Vitória da Conquista; depois, já na região de Itapetinga, foram expulsos da margem do Rio Catulé Grande para a Serra Couro D’Anta, 
posteriormente, colocados no centro da prometida "civilização" que ficava em Itaju do Colônia. Aqueles que não aceitaram a submissão catequista ou evangelizadora, fugiram para o litoral da Bahia, lugar de onde desapareceriam para sempre ao ser aculturados pelos povos Tupinambá e Pataxó.

\section{Consideração finais}

A condição da terra para o desenvolvimento agropastoril acabou por trazer uma rentabilidade econômica para os criadores de boi de Itatinga. Isto tornou-se notório quando a notícia, ao ser espalhada, atraiu novos investidores e aumentou a população do pequeno povoado. Aos poucos, de acordo com Nery (1995), a mata fechada acabou sendo substituída por um centro cada vez mais urbano.

Surgem, então, ritmos de trabalho e a cultura que marcariam o "habitus" (re)produtor de uma nova definição social; aos poucos, foi totalmente esquecido o tanto que a sua ascensão urbana nascera da morte de outras culturas. Contexto no qual está inserido o extermínio do povo Mongoió e o aniquilamento dos animais. Ambos foram trocados por criadores (pecuaristas), vaqueiros e criatórios bovinos. Evidentemente, como mostrou a nossa pesquisa de 2007/2009, por muito tempo essa produção em nada utilizou dos conhecimentos tecnológicos ou científicos. O que havia era a exploração do solo, formando uma maior concentração de renda econômica.

Dentre os capitais, a primeira forma de representação constituída para a região de Itatinga, foi derivado do poder e do status quo em possuir a terra. Para tal, pouco importava aqueles novos moradores que para abrir novos pastos e aumentar o criatório bovino, significava extrair e queimar as florestas, motivo que, segundo Moreira (2009a, 2009b, 2013), conduziu à destruição quase que total da mata atlântica na região, entretanto, com isso materializava- se a formação urbana de Itapetinga, que por sua vez, passou a negar a existência do povo Mongoió. 


\section{Referências}

BAUMAN, Zygmunt. Comunidade: a busca por segurança no mundo atual. Rio de Janeiro: Jorge Zahar, 2003.

BERNARDO, Teresinha. Memória em branco e negro: olhares sobre São Paulo. $1^{\text {a }}$ Reimpressão. São Paulo, EDUC / FAPESP, 2007.

BONNEWITZ Patrice. Primeiras Lições: sobre a Sociologia de P. Bourdieu. Tradução Lucy de Magalhães. $2^{a}$ Edição. Petrópolis: Vozes, 2003.

BOSI, Ecléa. Memória e Sociedade. Lembranças de Velhos. São Paulo, $16^{\mathrm{a}}$ Edição. CIA das LETRAS, 2010.

BOURDIEU, Pierre. Gostos de Classes e Estilos de Vida. In: A sociologia de Pierre Bourdieu. (Org.) Renato Ortiz. São Paulo: Olho D’Água, 2003, p. 73-111.

Coisas Ditas. Tradução Cássia R da Silveira e Denise Moreno Pegorim; Revisão técnica Paula Montero. São Paulo: Editora Brasiliense S. A, 2004.

A Distinção: Crítica Social do Julgamento. Tradução: Daniela Kern e Guilherme j. F. Teixeira. São Paulo: Edusp. 2007a.

O Poder Simbólico. Tradução de Fernando Tomaz. 10a edição. Rio de Janeiro: Bertrand Brasil, 2007b.

A Economia das Trocas Simbólicas. Introdução, Organização e Seleção: Sergio Miceli. São Paulo: Perspectiva, 2007c.

CAMPOS, E. R. Itapetinga: a persistente busca pela sua história. Salvador/BA: Secretaria da cultura e Turismo, 2006.

CRUZ, Mônica Cidele da; COROZOMAE, Marcio Monzilar. O ENSINO DE LÍNGUA MATERNA NA ESCOLA INDÍGENA JULÁPARÉ. ISSN: 1806-0331 (Impressa). Revista Ecos, vol.18, Ano XII, nº 01 (2015), p. 317-332.

GOMES, Mauricio. Itapetinga: Quero Te Conhecer. Itapetinga-BA: Gráfica Moderna, 2002.

IVO. Isnara Pereira. Homens de Caminho: Trânsitos, Comércio e Cores nos Sertões da América Portuguesa - Século XVIII. Doutorado em História da Pós-Graduação da Faculdade de Filosofia e Ciências Humanas da Universidade Federal de Minas Gerais. Belo Horizonte. 2009, p. 391. Orientador: Prof. Dr. Eduardo França Paiva.

A conquista do sertão da Bahia no Século XVIII: Mediação cultural e aventura de um preto forro no Império Português. Trabalho Apresentado ANPUH - XXIII SIMPÓSIO 
NACIONAL DE HISTÓRIA - Londrina, 2005, p. 1-11. Disponível em http://anais.anpuh.org/pdf/ANPUH.S23.1278.pdf. Acessado em 23 de outubro de 2012.

JABUR, Judith de Moura. Histórias e Causos de Itapetinga. Vitória da Conquista: Edições UESB, 1998.

LARAIA, R. B. Cultura: um Conceito antropológico. 20 ed. Rio de Janeiro: Jorge Zahar, 2006.

LEVI STRAUSS, Claude. Antropologia Estrutural II. Líbrairle Plon, Direitos reservados às Edições Tempo Brasileiro Ltda. 1973.

MARX, Murillo. Cidade Brasileira. São Paulo: Melhoramentos / Edusp, 1980.

Nosso chão: do sagrado ao profano. $2^{\circ}$. Edição. São Paulo: Edusp,

2003.MONLEVADE, João. Educação pública no Brasil: contos e descontos. Distrito Federal: Idea Editora, 2 ${ }^{\mathrm{a}}$ Edição. 2001.

MOREIRA, Jussara. Representação dos Moradores da Cidade de Itapetinga Sobre a Universidade Estadual do Sudoeste da Bahia - UESB: A Construção de Um Olhar. Mestrado em Ciências Sociais. Área de concentração: Sociologia do Programa de PósGraduação em Ciências Sociais da Universidade Católica de São Paulo - PUC-SP. 2009, p. 1173. Orientadora Prof. ${ }^{\text {a }}$. Dra.Marisa do Espírito Santo Borin.

A IGREJA E A PRAÇA: Os Batistas e a sua Influência na Cultura Religiosa da Cidade de Itapetinga-Bahia (1938 a 2013). Doutorado em Ciências Sociais. Área de concentração: Sociologia do Programa de Pós-Graduação em Ciências Sociais da Universidade Católica de São Paulo - PUC-SP. 2016, p. 1-302. Orientadora Prof. a . Dr. Marisa do Espírito Santo Borin.

Memória e Representação Cultural de Itapetinga. In: Polifonias da Cidade: Memória, Arte e cidade. Organização: Yvone Dias Avelino e Marcelo Flório. São Paulo: D Escrever Editora, 2009, p. 129-151.

- Representação dos Moradores da Cidade de Itapetinga Sobre a Universidade Estadual do Sudoeste da Bahia: A Construção de Um Olhar. In: Ciências Sociais em Perspectiva de Diálogo. Organização Carlos Alberto Maciel [et al]. Vitória da Conquista: Edições UESB. 2013, p. 45-60.

NERY. Antônio da silva. Juvino Oliveira: Vida e Obra. Itapetinga-BA: Gráfica Dimensão, 1995.

OLIVEIRA, Nelma Gusmão. DE "CAPITAL DA PECUÁRIA" AO "SONHO DE PÓLO CALÇADISTA": A Constituição da Estrutura Urbana de Itapetinga BA. Dissertação de Mestrado Em Arquitetura e Urbanismo. Programa de Pós-Graduação em Arquitetura e Urbanismo. Universidade Federal da Bahia. Salvador: 2003, p. 1-236. Orientador: Prof. Dr. Antônio Heliodório Lima Sampaio. 
PEIXOTO, Afrânio. CARTAS JESUÍTICAS II: CARTAS AVULSAS. 1550 a 1568. N 7 e 8, dezembro. Imprensa Nacional: Rio de Janeiro, 1933, p. 05-38.

TEIXEIRA, Manuel A. C. "A Influência dos Modelos Urbanos Portugueses na Origem da Cidade Brasileira", Trabalho apresentado: IV Seminário de História da Cidade e do Urbanismo. In: História da Cidade e do Urbanismo. Anais do IV Seminário de História da Cidade e do Urbanismo, Rio de janeiro. Programa de Pós-Graduação em Urbanismo FAU/UFRJ Faculdade de Arquitectura e Urbanismo, Universidade Federal do Rio de Janeiro, 1997.

. "A Construção do Espaço Urbano do Brasil". In: N. da Silva, Maria Beatriz (org.): De Cabral a Pedro I: Aspectos da Colonização Portuguesa no Brasil. Lisboa: Livros Horizontes. 2001a.

A Praça na Cidade Portuguesa. Lisboa: Livros Horizontes. $2001 \mathrm{~b}$.

WIELD-NEWIED, Maximiliano. "Viagens ao Brasil: nos anos de 1815 a 1817". 1ª Ed. Tradutor: Edgard Süssekind de Mendonça e Flávio Poppe de Figueiredo. Organizador: Olivério Mário de Oliveira Pinto. São Paulo: Cia. Editora Nacional, 1942.

\section{FONTES ORAIS}

(B.) - História de vida. B é analfabeto, aposentado, tem noventa e nove (99) anos, reside em Itapetinga desde a década de 30 do século XX. (Etapas realizadas em 04, 12 e 18 de março, de 2008. Com o tempo aproximadamente de 20 minutos para cada etapa.).

OLIVEIRA, Terezinha Ribeiro Rocha. Memória. Recolhida pela pesquisadora na tarde do dia 13 de fevereiro de 2014. Totalizando 2:00h de gravação.

SANTOS, Jovino Francisco. Memória. (Neto do pioneiro de Itapetinga: Bernardino Francisco de Souza). O vídeo com a memória foi gravado em 13 de dezembro de 2010 por Sergio Gomes ARTS. Foi o próprio produtor quem nos cedeu o direito autoral para a transcrição e publicação em 20 de outubro de 2015.

\section{Notas}

${ }^{\mathrm{i}} \mathrm{O}$ primeiro nome de Itapetinga foi Itatinga, cujo significado no idioma Tupi, traduz da seguinte maneira: ita é pedra e tinga é branca.

ii A pesquisa de Campos (2006) apresenta que o nome Sertão da Ressaca, - território onde atualmente fica localizada a cidade de Vitória da Conquista -, tem duas possibilidades: derivado da invasão das águas dos rios sobre o sertão que assemelha ao fenômeno marinho e proveniente da palavra ressaco que corresponde à funda baía de mato baixo circundada por serras.

iii Segundo Campos (2006), a palavra Catulé é de origem indígena, por essa razão a escrita é com "u" e não com "o", como é utilizada pela população de Itapetinga (Catolé) ou transcrita nos registros oficiais. Originalmente, 
Katu'le significava o mesmo que pati, ou seja, era uma planta conhecida como coco-da-quaresma, que foi dizimada na região pela colonização e civilização do pasto. Chamamos a atenção que no presente artigo será respeitada o padrão da escrita "Catulé" seguindo a língua nativa.

iv Com o objetivo de identificar prioridades temáticas definidas a partir da realidade local, possibilitando o desenvolvimento equilibrado e sustentável entre as regiões, o Governo da Bahia passou a reconhecer a existência de 27 Territórios de Identidade, constituídos a partir da especificidade de cada região. O Território de Identidade Médio Sudoeste da Bahia - BA é composto por treze (13) municípios: Caatiba, Firmino Alves, Ibicuí, Iguaí, Itambé, Itapetinga, Itarantim, Itororó, Macarani, Maiquinique, Nova Canaã, Potiraguá e Santa Cruz da Vitória. Possui uma Área (em Km²) de 11.753,41; População Total (hab.) 247.180; População Urbana (hab.) 194.742; População Rural (hab.) 52.438; No de Famílias Assentadas - Reforma Agrária 225; Número de Projetos Reforma Agrária cinco (5); Área Reformada - Reforma Agrária (em hectares) 3.985; $\mathrm{N}^{\mathrm{o}}$ de estabelecimentos da agricultura familiar 7.543; Pessoal ocupado na agricultura familiar 18.622; e, Número de Pescadores 0 (IBGE, 2010); (INCRA 2014); Atlas do Desenvolvimento Humano (2014); Índice de Desenvolvimento Humano/PNUD (2014).

${ }^{v}$ Esse artigo começou a ser delineado ainda na época do mestrado, quando foi possível trazer uma primeira fala de um morador da cidade que se referia aos indígenas como pessoas que mereciam ser castigadas. Naquele momento da pesquisa resolvemos não publicar os nomes verdadeiros dos depoentes, assim chamamos pelas letras do alfabeto. Veja in: Representação dos Moradores da Cidade de Itapetinga Sobre a Universidade Estadual do Sudoeste da Bahia - UESB: A Construção de Um Olhar. Mestrado em Ciências Sociais. Orientadora Prof. ${ }^{a}$. Dra. Marisa do Espírito Santo Borin. Os dados constam nas referências bibliográficas deste artigo.

${ }^{\mathrm{vi}}$ Esse artigo traz dados da nossa tese de doutoramento realizado no ano de 2016. Nessa investigação, como foi acordado previamente, relatamos os nomes verdadeiros dos recordadores. Veja in: A Igreja e a Praça: os Batistas da Cidade de Itapetinga-Bahia (1938-2013), doutorado em Ciências Sociais. Orientadora Prof. ${ }^{\text {. }}$ Dra.Marisa do Espírito Santo Borin. Os dados constam nas referências bibliográficas deste Artigo

vii Jovino Francisco Santos, (1937-), gravou a sua memória em um Vídeo: Lembranças do Povo Camacã: In: Lembranças do meu Avô: Bernardino Francisco de Souza. Modalidade: esse Vídeo foi gravado em 13 de dezembro de 2010 por Sergio Gomes ARTS - curta metragem. A cópia do Vídeo com a memória do Senhor Jovino foi cedida gentilmente por: Sérgio Gomes de Carvalho em 20 de outubro de 2015, autorizando a essa pesquisadora a transcrição e publicação dos 30m de filmagem. Dados do depoente constam nas Fontes Primárias (Orais).

viii $\mathrm{O}$ trecho de terra que resta à Fazenda Onça até a atualidade fica localizada a $6 \mathrm{Km}$ ao Sul de Itapetinga.

ix A memória da senhora Terezinha Ribeiro foi recolhida por essa pesquisadora em 12 de fevereiro de 2013. Dados da depoente constam nas Fontes Primárias (Orais).

x A Região de Itapetinga era habitada pelos povos indígenas Mongoió (ou Kamakan). Com a chegada do "homem branco", concentrou as comunidades tribais na Serra Couro D' Anta. Com o desenrolar da "história civilizada", o desenvolvimento urbano e a extensão pastoril, viram-se obrigados a evadir cada vez mais, avançando rumo ao litoral (MOREIRA, 2009).

xi Essa visão do determinismo biológico, utilizada também em Itapetinga em seus primórdios foi baseada nos conceitos evolucionistas que traziam à tona a discussão sobre aqueles que consideravam, por exemplo, o indígena das sociedades não europeias, como primitivo, portanto antecessor do homem civilizado (LARAIA, 2006).

xii A Entrevista de (B), presente em nossa Dissertação, foi concedida a Pesquisadora através de sua história de vida em 18 de março de 2008. Dados do depoente constam nas Fontes Primárias (Orais).

xiii Por ainda ser uma região cheia de pedras brancas ganhou o nome de Itatinga. (Informações colhidas pela pesquisadora, entre os entrevistados da história de vida em 2008).

xiv Decreto Estadual de ${ }^{\circ}$. 8.499, de 22 de junho de 1933 - Distrito de Vitória da Conquista. Com a expansão econômica, "no dia 30 de março do ano de 1938, Decreto Estadual n". 10.724, sede elevada à categoria de Vila" (GOMES, 2006, p.23).

${ }^{x v}$ Dados retirados das Cartas Avulsas dos Jesuítas escritas de 1550 a 1568, publicadas originalmente no Brasil em 1887. As suas referências se encontram na bibliografia desse artigo.

xvi Ver nota de rodapé número anterior.

xvii Derivada do Tupi a palavra Pindorama ou "Terra das Palmeiras" seria o nome dado pelos nativos as terras brasileiras quando foi invadida pelos portugueses (MONLEVADE, 2001).

xviii Segundo Campos (2006), o Rio Pardo percorre uma extensão de 565 km, sendo 220 km no território mineiro, da nascente, no município de Rio Pardo de Minas, a cerca de $750 \mathrm{~m}$ de altitude, até a foz em Canavieiras, no 
estado da Bahia, quando deságua no Oceano Attântico, a $18 \mathrm{~km}$ acima da foz do Rio Jequitinhonha. Seus principais afluentes são, pela margem esquerda, os ribeirões Salitre, Ribeirão e Vereda e os rios São João do Paraíso e Catulé Grande (região de Itapetinga), e, pela margem direita, os rios Mosquito (região de Macarani e Maiquinique, ambas localizadas no Sudoeste da Bahia).

xix $\mathrm{O}$ arraial da Conquista, de acordo com Campos (2006), antes era área distrital de Caetité, foi elevada à Vila através da Lei Provincial n ${ }^{\circ} 124$, de 19 de maio de 1840. Pelo ato de $1^{\circ}$ de julho de 1891 , a Vila da Victória transformou-se em cidade, recebendo, simplesmente, o nome de Conquista. Através da Lei Estadual N. ${ }^{\circ} 141$, editada em dezembro de 1943, o nome do Município foi novamente modificado e, a partir de 1944, passa ser chamado de Vitória da Conquista.

xx A Doutora em Linguística Mônica Cidele da Cruz, que é docente da Universidade do Estado de Mato Grosso, e o Professor Marcio Monzilar Corozomae, que pertence à Escola Estadual Indígena JuláParé, situada na Aldeia Umutina na área rural de Barra do Bugres (MT) esclarecem que "A língua Umutína é classificada como pertencente à família linguística Bororo, do tronco Macro-Jê. Atualmente, trinta (30) dos seus últimos remanescentes vivem na terra indígena localizada entre os rios Bugres e o Paraguai, a $15 \mathrm{Km}$ da cidade de Barra do Bugres-MT, juntamente com diversas etnias, [...] Os Umutina são monolíngues em português e, dentre eles, há apenas dois anciãos na aldeia, de 75 e 95 anos de idade, considerados os "lembrantes" da língua. Nos últimos anos, a escola e a comunidade indígena Umutina vêm desenvolvendo um trabalho bastante interessante de revitalização da língua materna e da cultura indígena" (CRUZ; COROZOMAE, 2015, p. 317). A referência deste trabalho consta em nossas referências bibliográficas.

xxi A viagem ao Brasil de Wied-Neuwied (1942) forneceu-lhe o reconhecimento sobre as línguas faladas em seu interior, pois, até então eram mais conhecidas o Tupi e o Guarani. A narrativa da viagem do Príncipe, também traz uma riqueza de detalhes sobre as diversas culturas formadas por crenças, hábitos, vestimentas, adornos, cerâmicas e maneiras de vidas dos nativos do interior brasileiro

xxii O rio Catulé Grande (Sudoeste da Bahia), com aproximadamente $80 \mathrm{~km}$ de extensão, nasce em Barra do Choça e deságua no Rio Pardo. Em Itapetinga percorre um curso de 9,5 km dentro da área urbana.

xxiii Para compreender a divergência entre os índios e os sertanistas, na região da Ressaca, consultar o livro "Viagem ao Brasil" de Maximiliano Wied-Neuwied. Publicado em 1820 sob o título "Reise nach brasilien in den jahren 1815 bis 1817". A indicação da versão em português do livro consta em nossas referências bibliográficas.

xxiv Os dados foram retirados da pesquisa de Emerson Ribeiro Campos (2006, p. 123).

xxv Em 1517, após inúmeras rivalidades entre os ortodoxos e heterodoxos franciscanos, de acordo com Campos (2006), o Papa Leão X dividiu-os em dois grupos distintos e independentes, cada qual com o seu próprio ministério. Dentro dessa divisão, no ano de 1520, surgiu, a partir da Ordem dos Frades Menores (OFM), a comunidade dos Capuchinhos. Foram eles que se estabeleceram no território da Bahia e passaram a catequizar ou domesticar os indígenas, sendo os únicos permitidos a atuar entre os índios, a partir do século XVII, após a lei de expulsão dos jesuítas comandada pelo Marquês de Pombal.

xxvi A Lei estadual n ${ }^{\circ}$ 2.042, de 12 de agosto de 1927, criou o Município de Itambé, mas, o seu território somente foi desmembrado de Conquista através do Decreto Estadual no 11.089 de 30 de novembro de 1938.

xxvii Local em que foi formada a cidade de Itapetinga, nessa época, distrito de Conquista.

xxviii Naquele período, Getúlio Vargas (Presidente do Brasil), "instituiu a lei de $\mathrm{n}^{\circ} .5 .901$ de 23 de outubro de 1943, normatizando a divisão administrativa e judiciária do País, [assim], localidades com a mesma denominação, prevalecia na seguinte ordem de preferência: Capital, Comarca, Termo, Município, Distrito (ART. $7^{\circ}$, I); localidade da mesma categoria com o mesmo nome, quem o possuir a mais tempo (ART. $7^{\circ}$, II). Itatinga estava enquadrada em ambos os itens (CAMPOS, 2006, p. 145). A Vila de Itatinga teve, que adicionar ao seu nome o termo "PE", se transformando em Itapetinga, pois, existia no estado de São Paulo, um local que se chamava Itatinga.

xxix Marx (2003) cita várias formas de festas sagradas, como exemplo fala das comemorações dos santos, das recepções aos bispos e dos coroamentos de príncipes e princesas, quanto as festas profanas, essas podiam ocorrer até mesmo em dia de feira, na comercialização dos produtos, nas inaugurações e etc. 


\section{Sobre a autora}

Jussara Tânia Silva Moreira. Mestre e Doutora em Ciências Sociais - área de concentração em Sociologia - pela Pontifícia Universidade Católica de São Paulo - PUC/SP. Professora Adjunta da Universidade Estadual do Sudoeste da Bahia (UESB), Campus de Itapetinga. Vinculada ao Núcleo de Pesquisa e Extensão Gestão em Educação e Estudos Transdisciplinares (NUGEET). Endereço Eletrônico: jussamoreira@oi.com.br

Recebido: 01.07.18

Aprovado: 26.07.18 